\title{
LA PRESENCIA DE REPRESENTACIONES VISUALES DE CONTENIDO RELIGIOSO EN LA ESCUELA PÚBLICA CONSTITUCIONALMENTE LAICA: UN ESTUDIO EXPLORATORIO EN AULAS DE EDUCACIÓN INFANTIL EN COLOMBIA
}

\author{
THE PRESENCE OF VISUAL REPRESENTATIONS WITH \\ RELIGIOUS CONTENT IN CONSTITUTIONALLY SECULAR \\ PUBLIC SCHOOL: A STUDY IN EARLY CHILDHOOD \\ EDUCATION CLASSROOMS
}

\author{
Vladimir MARTÍNEZ-BELLO \\ Zorayda BELLO DE MARTÍNEZ \\ Ángela MARTINEZ-ROJAS \\ Universitat de València
}

Recibido: 7/7/2016

Aceptado: 5/9/2016

Para citar este artículo / To cite this article:

Martínez-Bello, Vladimir; Bello de Martínez, Zorayda y Martínez-Rojas, Ángela. «La presencia de representaciones visuales de contenido religioso en la escuela pública constitucionalmente laica: un estudio exploratorio en aulas de educación infantil en Colombia». En Nieves Montesinos Sánchez y Beatriz Souto Galván (coords.), Laicidady creencias. Feminismo/s, 28 (diciembre 2016): 345-369, DOI: 10.14198/fem.2016.28.14

Para enlazar con este artículo / To link to this article:

http://dx.doi.org/10.14198/fem.2016.28.14 


\title{
Resumen
}

Una de las manifestaciones que genera confusión en el marco de la relación entre el Estado Laico, el principio de neutralidad y el ejercicio del derecho a la educación, es la presencia de símbolos religiosos en la escuela pública. El objetivo del estudio es analizar, a través de un sistema cuantitativo y cualitativo, la representación de las figuras humanas con contenido religioso en diez aulas de educación infantil de colegios públicos de una ciudad capital. En la mitad de colegios visitados existe presencia de figuras humanas con contenido religioso. Se observa una transformación del discurso que sobrepasa la representación del crucifijo. Los mensajes distorsionan el principio de neutralidad del Estado y se demuestra más una intención de educación religiosa que el desarrollo de la dimensión espiritual. Se aporta nueva información acerca del tratamiento de la religión y la dimensión espiritual en la educación infantil de la escuela constitucionalmente laica.

Palabras clave: escuela pública, símbolos religiosos, educación infantil, entorno escolar, representaciones visuales.

\begin{abstract}
One of the manifestations that creates confusion within the context of the relationship between the secular state, the principle of neutrality and the exercise of the right to education, is the presence of religious symbols in public schools. Therefore, the main aim of this study is to analyse the representation of human figures with religious content in the early childhood education classrooms of public schools in a capital city. In half of schools visited there is a significant presence of human figures with religious content. It has been shown a transformation of discourse which surpasses the representation of the crucifix is observed. The visual representations distort the principle of neutrality of the state and their show more an intention of religious education that the development of the spiritual dimension. Our study gives new information about the treatment of religion and spiritual dimension in the early childhood education curriculum within the constitutionally secular school.
\end{abstract}

Keywords: public school, religious symbols, early childhood education, school environment, visual representations. 


\section{INTRODUCCIÓN}

\subsection{La laicidad del Estado Colombiano}

El artículo 19 de la Constitución Política de Colombia (Constitución de Colombia), respecto a la libertad religiosa establece: «Se garantiza la libertad de cultos. Toda persona tiene derecho a profesar libremente su religión y a difundirla en forma individual o colectiva. Todas las confesiones religiosas e iglesias son igualmente libres ante la ley». Por su parte, la ley por la cual se desarrolla el Derecho de Libertad religiosa sostiene en su artículo 2 que:

Ninguna Iglesia o Confesión religiosa es ni será oficial o estatal. Sin embargo, el Estado no es ateo, agnóstico, o indiferente ante los sentimientos religiosos de los colombianos». Por tanto, el Estado Colombiano no se vincula con la práctica expresa de una religión o con un grupo de sentimientos religiosos. (Ley 133 de 1994)

Dicho marco constitucional y legislativo ha sido interpretado por la Corte Constitucional Colombiana estableciendo el carácter laico del Estado colombiano. Respecto a la igualdad de religiones, cultos e iglesias en el sistema jurídico colombiano con la Constitución de Colombia «se estableció un Laicismo de Estado, que otorga a éste una función arbitral de las referencias religiosas, de plena independencia, frente a todos los credos» (Sentencia C-568/93). Posteriormente, la citada Corte señaló que:

En el ordenamiento constitucional colombiano hay una separación entre el Estado y las iglesias porque el Estado es laico, en efecto, esa estricta neutralidad del Estado en materia religiosa es la única forma de que los poderes públicos aseguren el pluralismo y la coexistencia igualitaria y la autonomía de las distintas confesiones religiosas (Sentencia C-350/94.)

En un reciente pronunciamiento, la Corte señaló que:

Una garantía esencial de la libertad religiosa será la laicidad estatal, adquiriendo esta última el carácter de elemento esencial dentro del Estado democrático en cuanto componente axial en el proceso de concreción de principios como el pluralismo ideológico y religioso, base conceptual de la tolerancia inclusiva que se predica en toda democracia sustancial (Sentencia C-766/2010.) 
En lo que respecta al ámbito educativo, el artículo 67 de la Constitución Colombiana establece que «la educación es un derecho de la persona...» y que «el Estado, la sociedad y la familia son responsables de la educación». En esta línea, el artículo 68 de la Constitución es muy claro en señalar las limitaciones y facultades entre el equilibrio de la educación religiosa y el derecho de la educación al señalar que "Los padres de familia tendrán derecho de escoger el tipo de educación para sus hijos menores. En los establecimientos del Estado ninguna persona podrá ser obligada a recibir educación religiosa». Por su parte, el parágrafo del artículo 23 de la Ley 115 de 1994 señala que la educación religiosa deberá ofrecerse en todos los establecimientos educativos, sin que ello implique que los miembros de la comunidad académica tengan la obligación de recibirla.

Prieto señala que con la Constitución de Colombia el Estado adoptó un sistema no confesional, vinculado con el concepto de laicidad positiva, esto es que ampara y protege la naturaleza del derecho fundamental de libertad religiosa (62). Esta forma de entender la laicidad, según el autor, se ve reflejada en el hecho de que el Estado no es indiferente ante los sentimientos religiosos y de protección de las personas en sus creencias, tal como señala la Ley 133 de 1994, que regula el derecho de libertad religiosa. En definitiva, como recuerda Sanabria, la república laica es de todos, y no de los creyentes o de los ateos. Esto no significa que el Estado esté vacío de valores, sino por el contrario, que se encuentra fundado en los derechos más universales que permiten una unión que no impide la diferencia sino que organiza la convivencia solidaria (Sanabria 55).

\subsection{El principio de neutralidad estatal como concreción de la laicidad del Estado}

Tal y como se mencionó en el punto anterior, la jurisprudencia colombiana, de forma unánime y reiterada, ha establecido la necesidad de garantizar el principio de neutralidad estatal. Para la Corte Constitucional la separación entre las Iglesias y el Estado incluye los principios de Estado laico, neutralidad y prohibición de persecución.

La sentencia C-512/2003 reconoció «el principio de separación entre las iglesias y el Estado, que incluye la neutralidad del Estado laico en asuntos religiosos y la prohibición de cualquier acción propia de un estado confesional». En dicha sentencia se recuerda que la Constitución y la Ley imponen al Estado laico el deber de ser neutral frente a las diversas manifestaciones religiosas. Pardo-López señala que en el ámbito del principio de laicidad que desemboca en el deber de neutralidad del Estado en materia religiosa, el Estado 
no solo debe ser neutral/imparcial ante las distintas confesiones, sino, «debe aparecer como tal» (192). Recientemente, señaló la Corte que «se establece en la Constitución un Estado laico, el cual tiene un significado preciso para el contenido del derecho de libertad religiosa y, de forma correlativa, respecto de las acciones que el estado puede llevar» (Sentencia C-766/2010). La misma sentencia de constitucionalidad establece que la libertad religiosa que sustenta la laicidad del Estado genera unos límites para el mismo Estado. Estos límites, sostiene la Corte, se manifiestan a través del establecimiento del principio de neutralidad estatal ante las confesiones religiosas. Para la Corte este principio:

Comporta que las actividades públicas no tengan fundamento, sentido $\mathrm{u}$ orientación determinada por religión alguna -en cuanto confesión e institución- de manera que las funciones del Estado sean ajenas a fundamentos de naturaleza confesional (Sentencia C766/2010).

Una de las manifestaciones que ha generado confusión y ha facilitado el análisis de la relación entre el Estado Laico, el principio de neutralidad y el ejercicio del derecho a la educación, ha sido la presencia de símbolos religiosos en la escuela pública. Veamos a continuación qué señala la doctrina respecto a este punto. Para Amérigo y Pelayo un símbolo religioso «es la forma de representar una idea o creencia religiosa, cuyo significado se concreta por convención social» (10). Para Llamazares-Calzadilla, «la escuela pública no puede en ningún caso ser una escuela de adoctrinamiento o proselitista, y no debe nunca establecer exigencias en materia de fe» (170). Como sostiene Polo-Sabau en el marco de la necesaria neutralidad ideológica del Estado

La presencia en un centro público de un símbolo primordialmente religioso que expresa de algún modo una opción preferente del Estado por una determinada religión o le otorga a esta, al menos, una posición predominante en ese ámbito objetivo, puede ser considerada, por sí misma, incompatible con dichos principios. (290)

Amérigo y Pelayo señalan que la presencia de símbolos religiosos en los centros educativos públicos debe tener en cuenta la especial protección de los menores con el fin de evitar el adoctrinamiento (60). En la misma línea, LlamazaresCalzadilla señala:

La presencia de la cruz en las aulas ejerce un particular influjo: tiene un carácter evocativo, es decir, representativo de la fe que simboliza. Así, no se puede negar su influencia sobre los alumnos. Su presencia propone la fe que simboliza como un ejemplo, e invita a seguir dicha fe que, aparentemente, es también la del Estado (170).

En definitiva, como sostienen Amérigo y Pelayo, la neutralidad evita la confusión entre las funciones y finalidades de los poderes públicos y las entidades 
religiosas, en la cual la existencia de símbolos religiosos institucionales en instituciones públicas «podría originar confusión y por ello, la laicidad se colocaría como primer límite» (12). Como señala Hermida-Del Llano (2011) «del mismo modo que el Estado no puede prohibir ni promover ninguna religión concreta, tampoco puede adoptar oficialmente una creencia religiosa o exigir que los individuos deban o no tener alguna» (135).

Si los establecimientos educativos a pesar de no utilizar los símbolos religiosos como medios de proselitismo de manera expresa, incorporan su presencia en los centros, el respaldo de la escuela por el significado religioso representado por el símbolo podría tener un efecto en aquellos estudiantes y familias que no se identifican con él (Zhurnalova-Juppunov 485). En esta línea, la autora sostiene que se puede presentar un mayor riesgo para aquellas minorías religiosas de proyectar en las aulas sus símbolos religiosos por la improbabilidad de que sus símbolos puedan tener un impacto cultural significativo. Por tanto, los establecimientos públicos, y en especial las aulas, deben procurar mantener la escrupulosa neutralidad porque su presencia es contraria al principio de laicidad (Amérigo y Pelayo 63).

\subsection{La jurisprudencia del Tribunal Europeo de Derechos Humanos: un ejemplo}

Debido a la escasa jurisprudencia sobre la constitucionalidad de la presencia de símbolos religiosos en las escuelas públicas colombianas, una vez visto el tratamiento de la doctrina, se presenta a manera de ejemplo un caso en Europa discutido por el Tribunal Europeo de Derechos Humanos (TEDH). El caso, conocido como caso Lautsi, se basó en la presentación de una demanda ante el TEDH por la retirada de un crucifijo en una escuela pública italiana, situación que fue dirimida en primera instancia, por la Sección Segunda del Tribunal (TEDH 2009) y en apelación por la Gran Sala (TEDH 2011) como recurso presentado por el gobierno italiano. Brevemente, la señora Lautsi se dirigió al TEDH por la violación del artículo 2 del Protocolo No. 1 de la Convención Europea de Derechos Humanos y el artículo 9 de la Convención Europea de Derechos Humanos. La sección Segunda del Tribunal aceptó la petición de la demandante, es decir, tuteló los derechos invocados señalando al colegio público la retirada del crucifijo por violación de la Convención. En particular la sección Segunda esgrimió que el Estado no puede imponer creencias, ni siquiera simbólicamente, al dejar un símbolo religioso en el aula (espacio donde hay personas dependientes o vulnerables) como son las aulas donde están los niños. A su vez, esgrimió que al ser el crucifijo un símbolo perteneciente a la iglesia católica, el Estado vulneró la obligación de neutralidad en 
la educación pública, en el cual esos símbolos en los muros son poderosos símbolos externos que violan la neutralidad del entorno educativo y producen adoctrinamiento. Por el contrario, dos años después, la Gran Sala determinó que la presencia de estos símbolos no vulneraba la neutralidad educativa y la imparcialidad por parte del Estado. La Gran Sala aceptó que el crucifijo es un símbolo religioso pero vinculado con las tradiciones históricas y culturales italianas.

\subsection{La dimensión espiritual y la educación religiosa en el ámbito de la educación infantil}

La Convención sobre los derechos del niño, adoptada por la Asamblea de la Organización de Naciones Unidas (ONU) el 20 de noviembre de 1989 (ONU 1989) y ratificada por el Estado colombiano mediante la Ley 12 de 1991, reconoce en su artículo 14 que los Estados Partes respetarán el derecho del niño a la libertad de pensamiento, de conciencia y de religión. A su vez, el artículo 27 estipula que los Estados Partes reconocen el derecho de todo niño a un nivel de vida adecuado para su desarrollo físico, mental, espiritual, moral y social». Como sostiene el comentario general número 7 del Comité de Derechos del Niño de la ONU (ONU 2005), las niñas y los niños captan activamente las dimensiones físicas sociales y culturales del mundo en el que viven aprendiendo progresivamente de sus actividades y de sus intenciones con otras personas. Además, el comentario número 5 del Comité de los Derechos del Niño establece que el artículo 6 de la Convención de los Derechos del Niño (ONU 1989), exhorta a los Estados a interpretar el término «desarrollo» en el sentido más amplio, es decir como concepto que abarca el desarrollo físico, mental, espiritual, moral, psicológico y social de las niñas y los niños.

En este sentido, en la sección de los Fines de la Educación de la Ley 115 de 1994, el inciso 1 del artículo 5 señala que la educación se desarrollará atendiendo a «El pleno desarrollo de la personalidad sin más limitaciones que las que le imponen los derechos de los demás y el orden jurídico, dentro de un proceso de formación integral, física, psíquica, intelectual, moral, espiritual, social, afectiva, ética, cívica y demás valores humanos». Respecto al currículo de educación infantil, el artículo 15 de la ley 114 define la educación preescolar como la «ofrecida al niño para su desarrollo integral en los aspectos biológico, cognoscitivo, sicomotriz, socio-afectivo y espiritual, a través de experiencias de socialización pedagógicas y recreativas». En particular, el inciso h señala «El reconocimiento de su dimensión espiritual para fundamentar criterios de comportamiento». Finalmente, el Ministerio de Educación, a través del programa de lineamientos curriculares, señaló que el desarrollo de la dimensión espiritual 
en el currículo de educación infantil le corresponde en primer lugar al núcleo familiar y en segundo lugar a la institución escolar. Señala el documento, en el desarrollo de esta dimensión define la espiritualidad como la oportunidad para «establecer y mantener viva la posibilidad de trascender como una característica propia de la naturaleza humana» (Ministerio de Educación 21). El documento señala a su vez que «el espíritu humano crea y desarrolla mediante las culturas y en las culturas un conjunto de valores, de intereses, de aptitudes, actitudes de orden moral y religioso con el fin de satisfacer la necesidad de trascendencia que lo caracteriza» (21).

Para los propósitos de este estudio, en las líneas siguientes se esbozará brevemente las principales características y atributos que han sido reseñados en el ámbito educativo sobre el desarrollo de la dimensión espiritual. Por ejemplo, Alexander y McLaughlin señalan que la educación para la espiritualidad puede desarrollarse bien dentro de un contexto religioso o en un contexto no religioso (361). Respecto al primero, Hyde ha identificado cuatro características de la espiritualidad de niñas y niños en escuelas primarias católicas: la sensación sentida, la integración de la conciencia, el tejido de los hilos de significado, y las misiones espirituales (120). A su vez, tal como sostiene Grajczonek dentro de un contexto religioso como son las escuelas católicas o cristianas, el desarrollo de la dimensión espiritual de niñas y niños en la primera infancia hace parte del desarrollo integral de su desarrollo religioso (112). Es de anotar, como es habitual que dichas concepciones estén vinculadas a opciones de la escuela privada, y en particular, religiosas. Respecto al segundo, casos como en Aotearoa, Nueva Zelanda, señalan algunas prácticas educativas en las aulas vinculadas con la comida y la alimentación en el cual el compartir estos espacios con otros es un punto de inicio para analizar las experiencias espirituales de las niñas y los niños (Bone 2005, 310). La misma autora en un estudio cualitativo desarrollado en tres colegios de educación infantil encontró que algunas comunidades educativas, a través del uso de la escritura, construyen espacios donde se establecen relaciones con base en compresiones conjuntas de espiritualidad como parte de una perspectiva integral hacia la educación (Bone 2008, 352). Recientemente, Harris señaló la relación que juega el medio natural en el desarrollo de la espiritualidad para ayudar en la identificación de los intereses, necesidades y fortalezas a través de las relaciones entre las familias y la comunidad (104).

En definitiva, como sostiene McLoughlin, en el desarrollo espiritual en el ámbito escolar, surgen dos importantes preguntas (181). Por una parte, cómo deben ser propiamente entendidos la espiritualidad y el desarrollo espiritual; y dos, cómo se justifica la influencia educativa en relación con la dimensión 
espiritual. En cualquier caso, señala la autora, es necesario diferenciar el espacio que ocupa o debe ocupar el desarrollo de la dimensión espiritual en un contexto vinculado con la religión o sin ella, y en particular en el ámbito de la escuela pública y las escuelas religiosas. Bajo esta línea, Nye y Hay sostienen que el profesorado podría considerar en primer lugar la espiritualidad de los niños pequeños y el desarrollo espiritual por delante de su desarrollo religioso (144).

\subsection{El papel del entorno escolar en la primera infancia: Especial atención a los mensajes vertidos en los muros de las aulas}

El comentario 1 del Comité de Derechos del Niño de la ONU sobre el derecho a la educación (ONU 2001), señaló que en él «se incluyen no sólo los elementos integrantes del plan de estudios, sino también los procesos de enseñanza, los métodos pedagógicos y el marco en el que se imparte la educación, ya sea en el hogar, en la escuela u otros ámbitos» (parágrafo 8). A su vez el Comité recuerda que «el propio entorno escolar debe reflejar la libertad y el espíritu de entendimiento, paz, tolerancia, igualdad entre los sexos y amistad entre todos los pueblos, grupos étnicos, nacionales y religiosos y personas de origen indígena» (parágrafo 19). Por otra parte, en el ámbito de la didáctica de la educación infantil en los últimos años se ha propuesto que el ambiente natural y construido que acompaña las aulas de educación infantil sea sometido a una supervisión con el objetivo de modificar prácticas que excluyan y distorsionen la formación integral de las niñas y los niños. Como sostiene Tarr, el reto del profesorado en educación infantil consiste por tanto en pensar más allá del papel decorativo de los muros, y dar el salto hacia cómo estos pueden ser usados efectivamente como parte del entorno educativo $(2004,90)$. Por tanto, dichos imaginarios que hacen parte del entorno educativo, algunos estereotipados o no, conforman la cultura del aula, a pesar de que dichos mensajes no hagan parte del currículo explícito.

A los efectos de lo hasta aquí descrito, no hemos encontrado evidencias reportadas de manera sistemática sobre la presencia de símbolos religiosos en aulas de escuelas públicas en el ámbito iberoamericano. Sin embargo, se ha discutido por ejemplo, los alcances de los principios de neutralidad y laicidad respecto a su presencia en tribunales de justicia en Brasil (Ranquetat-Júnior 1). Recientemente, Souto-Galván analizó las alternativas más adecuadas para gestionar, desde la perspectiva de género, la diversidad cultural en el ámbito escolar español en el marco de usos de símbolos religiosos en la escuela pública (6). Barrera-Rivera analizó cómo las prácticas de las diferentes religiones, sus estrategias de influencia y el pluralismo religioso en Brasil tienen importantes 
injerencias en el campo de los derechos ciudadanos (150). Además, Cobos Campos, a pesar de encontrar escasa construcción jurisprudencial alrededor del derecho a la libertad religiosa en México, señala que cierto acercamiento se ha venido produciendo en Latinoamérica (63). En definitiva, para AlvaradoBedoya en países como Colombia, la permanente transgresión del principio de laicidad y aún más evidente la ausencia de procesos de secularización garantes de una noción democrática hacen difícilmente aplicable el mandato constitucional (601).

Por esa razón, el presente estudio tiene como propósito contribuir en el estudio de la laicidad, la aconfesionalidad y la neutralidad de las instituciones del sistema educativo público. Por tanto, el objetivo del presente estudio consiste en describir la representación de las figuras humanas con contenido religioso en las aulas de educación infantil de una muestra de colegios públicos de una ciudad capital colombiana. La hipótesis central del estudio es que en una gran proporción de aulas de educación infantil de la ciudad objeto de estudio tiene representado en sus muros la presencia de símbolos de religiosos. Como segunda hipótesis se sostiene que aquellas aulas de educación infantil con presencia de símbolos religiosos serán pertenecientes a la religión católica.

\section{METODOLOGÍA}

\subsection{Muestra}

Se realizó una búsqueda de colegios públicos que imparten el grado de educación infantil (Transición) en la ciudad de Bucaramanga, Colombia, a través del registro público de la Alcaldía Municipal. La ciudad de Bucaramanga es la capital del Departamento de Santander y cuenta con una población total de 526.056 habitantes. El acceso a los centros fue informado a las directivas del mismo. Los criterios de inclusión de los colegios fueron: 1. Establecimientos públicos; 2. Pertenecientes a la ciudad de Bucaramanga. 3. Ubicados en la zona urbana. En total, participaron diez colegios públicos. De cada colegio se escogió un aula. En los colegios donde había más de un aula de los cuáles se escogieron al azar, a través de una tabla de números, un aula de educación infantil por cada uno de ellos. En los casos una sola aula por colegio, esta fue seleccionada. En Colombia el grado de Transición es el nivel obligatorio del nivel preescolar (Colombia 1994).

\subsection{Unidades de muestro}

De cada una de las aulas se procedió a seleccionar las unidades de registro. Las unidades de registro fueron aquellas imágenes que representasen una figura 
humana a través de fotografías, dibujos, figuras humanas artificiales, etc. Para la selección de las figuras humanas con contenido religioso, la imagen debía retratar un significado unívoco sobre la pertenencia a una religión.

\subsection{Recolección de la información}

Las unidades de muestreo captaron en formato fotográfico todas las representaciones visuales proyectadas en los muros de las aulas de educación infantil. En ninguna de las aulas estudiadas se observaron crucifijos. Del total de las imágenes, se seleccionaron las figuras humanas con y sin contenido religioso que fueron extraídas y puestas en un archivo de un procesador de texto para su posterior análisis. La muestra total fue de 170 imágenes en las diez aulas de los diez colegios. El promedio de imágenes con las figuras humanas por aula fue de 17 (+-12). En cinco aulas se encontraron imágenes de figuras humanas con contenido religioso. El promedio de imágenes religiosas por aula fue de 2 (+-2). En total se reportaron 12 figuras humanas con contenido religioso.

\subsection{Análisis de las imágenes}

El análisis de las imágenes se realizó en dos momentos. En el primero, se realizó un análisis cuantitativo sobre la presencia de imágenes religiosas en todas las aulas de educación infantil analizadas. En este proceso, se identificó la frecuencia y el porcentaje de acuerdo a la muestra total. En un segundo momento, se procedió a realizar un análisis cualitativo sobre aquellas representaciones visuales de figuras humanas con contenido religioso únicamente. Para ello se construyó un sistema de categorías e indicadores elaborado posteriormente a la recogida de la información.

\subsection{Sistema de categorías}

Las categorías e indicadores que se presentan en la Tabla 1 fueron construidas en tres momentos. En un primer momento, se procedió a realizar una primera revisión sobre los patrones, tendencias, etc. de los datos recogidos. En un segundo momento, se procedió a agrupar en categorías aquellas tendencias con entidad propia. Posteriormente, las participantes del grupo discutieron sobre los indicadores de las categorías y finalmente se procedió a construir el sistema definitivo (Ver Tabla 1). 
Tabla 1

Construcción de categorías

\begin{tabular}{|c|c|}
\hline Categorías & Características \\
\hline Religión & Católica; Otra \\
\hline Figura representativa & Jesús; Virgen María u otras; Ángeles; \\
& Divino Niño \\
\hline Dimensión elaboración & Comercial, construido \\
\hline Lugar donde su ubican & Encima del tablero; En otro lado \\
\hline
\end{tabular}

Fuente: Elaborada por las autoras

\subsection{Análisis estadístico}

Se realizó un análisis descriptivo de las frecuencias y los porcentajes de presencia de figuras humanas en cada uno de los colegios que hicieron parte de la muestra.

\section{RESULTADOS}

\subsection{Resultados cuantitativos}

\section{Figura 1}

Presencia de figuras humanas con contenido religioso

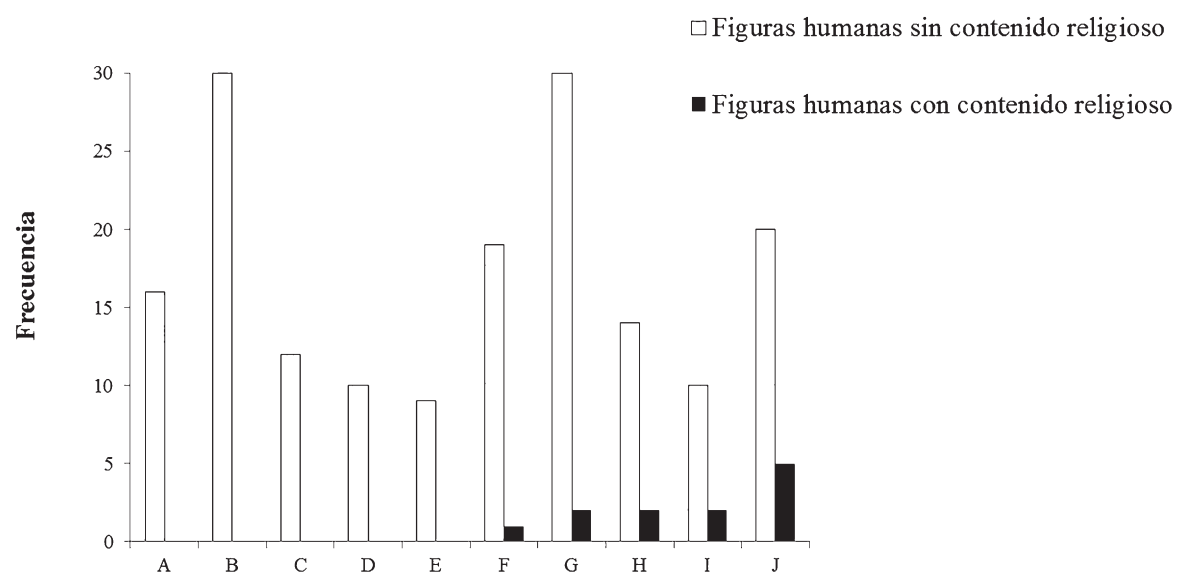

Fuente: Elaborada por las autoras 
Con el objetivo de describir la presencia de figuras humanas con contenido religioso en los muros, en la figura 1 se observan los principales resultados de 10 aulas de educación infantil. El 50\% de las aulas representa en las imágenes proyectadas en los muros una o varias imágenes de figuras humanas con contenido religioso. De la totalidad de imágenes en estos cinco centros, el 13\% de las figuras humanas representadas en los muros corresponde a figuras con contenido religioso.

De los diez colegios, en la figura 1 se observa la frecuencia de presencia de figuras humanas con contenido religioso en cinco de ellos (F, G, H, I, J). En particular para cada aula, se observa que la frecuencia de presencia en los colegios G, H e I, fue de dos, respectivamente. Esto equivale a un $7 \%, 14 \%$ y $20 \%$ de imágenes con contenido religioso en cada uno de estos colegios. En el colegio J, de las 19 imágenes en total, 1 correspondió a imágenes con contenido religioso ( $5 \%$ del total en ese colegio). Por su parte, el colegio con mayor presencia de figuras humanas con contenido religioso fue el colegio J. Se observa que la frecuencia de presencia fue de 5 imágenes con contenido religioso, valor equivalente a un $25 \%$ de la muestra total para ese colegio.

\subsection{Resultados cualitativos}

De los diez colegios analizados, en cinco existió presencia de figuras humanas con contenido religioso. En estos cinco colegios se contabilizaron y agruparon un total de 12 representaciones visuales de figuras humanas con contenido religioso. Con el objetivo de describir si la presencia de figuras humanas con contenido religioso en los muros de las aulas de educación infantil es perteneciente a la religión católica, respecto a la categoría «Religión», todas las figuras correspondieron a la religión católica. Respecto a la categoría «Figura representativa», se observó que ocho correspondieron a figuras de vírgenes (María, Lourdes, etc.), dos a Jesús y una por los indicadores ángeles y el Divino Niño, respectivamente. Respecto a la categoría «Dimensión elaboración», se encontró que nueve correspondieron al indicador comercial y tres al construido comercial. Es decir, se observaron más representaciones vinculadas con afiches, cuadros, almanaques, etc., mientras que las elaboradas de forma artesanal fueron menores. Respecto a la categoría «Lugar», se encontró que éstas estuvieron colocadas en los muros principalmente y de acuerdo a una ubicación más específica, algunas ubicadas en la parte superior central y otras en los muros laterales. En la tabla 2 se presentan a manera de ejemplo, algunas representaciones visuales encontradas en los muros de las aulas. 
Tabla 2

Ejemplos de representaciones visuales de figuras humanas con contenido religioso

\begin{tabular}{|c|c|c|c|c|}
\hline Virgen & Jesús & Ángeles & Divino Niño & Otras Vírgenes \\
\hline & & & & \\
\hline
\end{tabular}

Fuente: Elaborada por las autoras

\section{DISCUSIÓN}

En el ámbito de la didáctica de la educación infantil se sostiene que el entorno escolar participa activamente en la construcción del currículo escolar (StrongWilson y Ellis 44). Los entornos escolares son declaraciones públicas acerca de los valores educativos del centro escolar y del profesorado (Tarr 2004, 89) y por tanto el profesorado debe hacerse las siguientes preguntas: ¿Cuál es el propósito de los símbolos presentes en los muros? ¿Para quién están ahí? ¿Cómo pueden los muros reflejar la vida de las familias, su cultura y los intereses del estudiantado? ¿Cuáles son las concepciones acerca de cómo las niñas y los niños aprenden, y cómo son estas reflejadas en los muros? A continuación se presentan distintas opciones para interpretar mejor la razón de ser de dichas preguntas en el ámbito escolar del Estado constitucionalmente laico.

Tal como sostuvo la Corte Constitucional (Sentencia C-350/94), respecto a la igualdad de confesiones religiosas, «el carácter más extendido de una determinada religión no implica que esta pueda recibir un tratamiento privilegiado por parte del Estado». No obstante, de los resultados del estudio, el 50\% de los colegios analizados representan una o varias figuras humanas con contenido religioso (Figura 1). A su vez, en algunas aulas el porcentaje de presencia de figuras humanas religiosas supera el $20 \%$ del total de todas las representaciones humanas. Por tanto, la presencia de representaciones de figuras humanas con carácter religioso, señala una manifestación de la decisión política del profesorado y/o de la institución por transmitir una idea vinculada con la religión católica. Por tanto, de acuerdo a la segunda hipótesis, efectivamente, en las aulas de educación infantil con presencia de símbolos religiosos, las representaciones visuales son pertenecientes a la religión católica. Tarr señala que no solamente los mensajes explícitamente proyectados en las aulas de educación infantil están cargados de significados, sino que aquellos mensajes 
silenciados y no presentes en las aulas, transmiten un mensaje de ausencia, de invisibilidad que también hace parte del currículo transmitido a las niñas y a los niños $(2004,89)$. En este caso, la presencia de unos símbolos religiosos podría estar vinculada con el silenciamiento de otras, así como la confusión entre el desarrollo de la dimensión espiritual y el marcado interés de relacionarse con la religión, y en este caso, con una única religión. En esta línea, los resultados señalan una manifestación del currículo oculto o no explícito que vincula una única concepción del desarrollo de la dimensión espiritual del currículo de educación infantil. En definitiva, si la misma Ley 115 de 1994 en su artículo 24, sostiene que en los establecimientos del Estado ninguna persona podrá ser obligada a recibir educación religiosa, la presencia de símbolos religiosos como los señalados en este estudio, debería ser revisada y discutida.

\subsection{El principio de neutralidad del Estado en materia religiosa}

Como sostuvo la Corte en la sentencia C-512/2013, no tendría sentido trasladar al contexto religioso el enfoque adoptado en otros países respecto a las particularidades de cada Estado respecto de la cuestión religiosa. Por esa razón, nos centraremos en primer lugar en abordar la discusión a través de la jurisprudencia colombiana. Como se comentó previamente, la jurisprudencia de la Corte Constitucional ha establecido en reiteradas ocasiones la laicidad del Estado colombiano a través del principio de neutralidad en materia religiosa.

En particular, en la sentencia C-512/2003 la Corte establece en el marco de las posibles situaciones de violación de los principios de separación entre las iglesias y el Estado y el pluralismo religioso, una serie de criterios que cumplen la función de trazar la línea entre lo permitido y lo prohibido. Para la Corte está constitucionalmente prohibido: 1. Establecer una religión o iglesia oficial; 2. Que el Estado se identifique formal o explícitamente con una iglesia o religión; y 3. Que realice actos oficiales de adhesión, así sean simbólicos, a una creencia, religión o iglesia. De acuerdo con los resultados del presente estudio, la presencia de símbolos religiosos podría ser explicada a través de los dos últimos criterios. El hecho de que en los muros de aulas de educación infantil de colegios públicos exista presencia de figuras humanas con contenido religioso, es una forma de desconocimiento del principio de neutralidad que ha de orientar al Estado en materia religiosa. Es necesario recordar que los criterios previamente expuestos por la Corte fueron refrendados por la sentencia C-817/2011. Como señala la literatura, el entorno que rodea el hecho educativo, esto es, las prácticas, la comunicación entre los participantes, y los contenidos explícitos e implícitos presentes en las aulas, tienen marcadas connotaciones que han llegado a las aulas a través de una decisión o grupo de decisiones con marcado 
carácter ideológico. Sanabria sostiene que uno de los cuatro principios a través de los cuales la escuela laica puede transmitir interculturalmente valores éticos implica, discreción ética y confesional, y exclusión de todo privilegio dado a una religión o a una ideología (59). Por tanto, de los resultados del presente estudio, la presencia de figuras humanas con contenido religioso privilegia a una religión, en este caso a la católica, resultado muy alejado de una escuela centrada en la necesaria neutralidad frente al hecho educativo.

Porque el ejercicio del derecho a la educación es un servicio público, es dable concluir que los establecimientos educativos públicos deben aplicar el principio de neutralidad. Este principio «comporta que las actividades públicas no tengan fundamento, sentido u orientación determinada por religión alguna -en cuanto confesión e institución- de manera que las funciones del Estado sean ajenas a fundamentos de naturaleza confesional» (Sentencia C-766/2010). Por tanto, de acuerdo a los resultados de la presente investigación se observa claramente un desconocimiento de las exigencias promovidas por el principio de neutralidad estatal, en la medida en que como ha recordado la Corte Constitucional (Sentencia C-766/2010), cualquier que sea el ámbito competencial en el que se realicen las actividades con motivación o fundamentación religiosa, como es el caso de la proyección en los muros de las aulas de educación infantil de las escuelas públicas, se distorsiona dicho principio.

\subsection{La directa relación entre la dimensión espiritual y la religión}

La Ley 115 de 1994 establece que uno de los objetivos de la educación preescolar es el «reconocimiento de su dimensión espiritual para fundamentar criterios de comportamiento». De acuerdo a los resultados del presente estudio, parece ser que los mensajes vertidos en los muros de las aulas, esto es, la presencia de figuras humanas con contenido religioso católico, atiende más a una intención de educación religiosa que a la condición espiritual que dicha dimensión pretende mostrar. El inciso h de la ley en mención, establece el reconocimiento de la dimensión espiritual de la niña o del niño, pero en ningún momento promueve la transmisión e imposición de la dimensión espiritual como una manifestación centrada por ejemplo en una única religión (símbolos religiosos católicos). Tarr sugiere que los mensajes vertidos en los muros de las aulas de educación infantil están basados en parte en las concepciones del profesorado sobre qué es lo que les gusta a las niñas y los niños $(2004,90)$. Por tanto, si uno de los objetivos de la educación preescolar es el reconocimiento de dicha dimensión espiritual, ha de ser la de cada niña o niño y no una imposición del centro escolar o del profesorado. 
Como sostienen Nye y Hay, el profesorado ha de considerar el desarrollo de la espiritualidad del niño o la niña antes que el desarrollo religioso (144). No obstante, de acuerdo a los resultados del presente estudio, para que un grupo de símbolos religiosos proyectados alcance el $20 \%$ en un aula en particular (Figura 1), este comportamiento refleja una intención de transmitir ideas particulares sobre una religión. Además, dado el carácter interdisciplinar de la educación de la primera infancia, el legislador quiso vincular únicamente el desarrollo de la dimensión espiritual más que el trabajo de la educación religiosa en niñas y niños en la educación inicial. Por tanto, parece que, de acuerdo a la presencia de símbolos religiosos presentada en este estudio, y dado el carácter no solo aconfesional sino público de las instituciones visitadas, las aulas analizadas prefieren vincular la posibilidad de desarrollar dicha dimensión espiritual confundiéndola con el tratamiento de la educación religiosa.

Tal como sostuvo recientemente la Corte:

La neutralidad, derivada de la laicidad, no consistirá en la búsqueda por parte del Estado de un tratamiento igual a las religiones a partir de las actividades que éste realice en relación con ellas. La neutralidad estatal comporta que las actividades públicas no tengan fundamento, sentido u orientación determinada por religión alguna -en cuanto confesión o institución-, de manera que las funciones del Estado sean ajenas a fundamentos de naturaleza confesional (Sentencia C-766/2010.)

En este sentido, alguien podría justificar que en aras de promover la libertad, los establecimientos educativos públicos podrían invitar a proyectar figuras religiosas en el mismo número que las ya presentes. Sin embargo, la misma Corte fue clara en señalar que:

La igualdad no se logra motivando las funciones estatales con base en intereses de todas las religiones por igual-algo, por demás, de imposible realización en la práctica-, pues esta pretendida igualdad, en cuanto vincula motivos religiosos en las actividades estatales, sería diametralmente contraria al principio de secularidad que resultad ser el núcleo del concepto de laicidad estatal y, de su concreción, el principio de neutralidad (Sentencia C-766/2010).

En Colombia, así como en otros países iberoamericanos, de acuerdo a la revisión de literatura realizada, este tipo de discusiones no se presentan y se da por sentado casi naturalmente la vinculación del desarrollo de la dimensión espiritual con la religión. Se considera, a pesar de no contar con la evidencia, que dicho comportamiento ha sido asimilado por cierto sector del profesorado a través de la normalización de dichas manifestaciones en el currículo de la educación para la primera infancia. Tal como sostuvo la Corte (Sentencia C-350/94), respecto al tema de igualdad de confesiones religiosas, «el carácter 
más extendido de una determinada religión no implica que esta pueda recibir un tratamiento privilegiado por parte del Estado». Una alternativa por ejemplo, sería vincular a la discusión el análisis crítico de las propias prácticas por parte del profesorado para indagar por ejemplo si el uso de símbolos religiosos puede afectar la formación integral de las niñas y niños. Igualmente, que el profesorado se pregunte si las familias, así como las niñas y niños que asisten a sus aulas, al no profesar la religión de dichos símbolos, puedan sentirse afectadas de alguna manera. Igualmente, si se tiene en cuenta la voz del menor (desde una lectura contemporánea sobre el estatus activo de ciudadanía de la infancia) a la hora de utilizar dichas representaciones en las aulas. Oportunidades que debe darse el profesorado para valorar esa transmisión de significados.

\subsection{La crítica al argumento de pasividad de los símbolos religiosos en las aulas y en especial en la escuela pública}

Las aulas no son sitios políticamente neutrales sencillamente porque el currículo es una construcción social. En este marco se resumirán brevemente los argumentos encontrados en la sentencia del caso Lautsi para centrarse posteriormente en el argumento en contra de la pasividad de los símbolos religiosos en el entorno escolar.

Tres fueron los hechos más controvertidos extraídos y que pueden aplicarse al ámbito educativo de las sentencias referentes al caso Lautsi. El primero, el de la ausencia de evidencia sobre el impacto negativo en las niñas y los niños que tiene la presencia en los muros del símbolo religioso, alejándose de los argumentos esgrimidos por la sección segunda respecto a la situación frágil y de desarrollo de los menores. El segundo, que el símbolo no constituye un poderoso símbolo externo y que por tanto no puede ser considerado como parte integral del entorno escolar. Y el tercero, que el símbolo dada su «naturaleza pasiva» al estar solo colgado de los muros no se eleva al nivel de adoctrinamiento y por tanto no puede equiparse a la enseñanza religiosa obligatoria. Como señala Polo-Sabau en el análisis de las dos sentencias del Tribunal de Estrasburgo (Sección segunda y de la Gran Sala), la diferencia fundamental entre ambas sentencias está basada en la distinta valoración de la fuerza simbólica del crucifijo (285). En la primera, la presencia del símbolo religioso (crucifijo) es «un poderoso signo externo», mientras que en la segunda sentencia (de la Gran Sala), este símbolo religioso es un «símbolo esencialmente pasivo». Dice el autor que la clave radica en qué ha de entenderse por la pasividad del símbolo, situación de difícil análisis al vincular el Tribunal el grado de influencia de ese símbolo en el estudiantado. En palabras de Polo-Sabau de acuerdo a la postura de la Gran Sala, el crucifijo en las aulas no constituye 
un símbolo esencialmente pasivo por su no demostrada influencia sobre las mentes de los estudiantes (286). El mismo autor señala que para el TEDH la cuestión de si la presencia influye en el estudiantado queda sometida a una situación probatoria únicamente. Entonces, surge la duda de si el Tribunal hubiese señalado la incompatibilidad de la presencia de ese símbolo religioso en las escuelas públicas italianas si hubiese existido evidencia de la afectación bien psíquica, afectiva o moral de los estudiantes y de la familia (Polo-Sabau 286).

Por su parte, Haupt determina que la consideración de un símbolo religioso visual como pasivo es descriptivamente inexacta y doctrinalmente incoherente (822). Bajo esta línea, como sostiene Zoethout, la exhibición de símbolos religiosos en las escuelas públicas entra en contacto con la libertad religiosa, la libertad que tienen las familias de educar a sus hijos de acuerdo a sus convicciones y toca la posición del Estado respecto a la educación pública (287). Debido a que la educación pública es un servicio público garantizado por el Estado, el mismo Estado debe garantizar una actitud de neutralidad e imparcialidad hacia la religión. De no hacerlo, señala la autora, el Estado demostraría preferencia hacia una religión, que equivaldría a un adoctrinamiento por parte del Estado. Considerar, y parece ser esa fue la línea de pensamiento de la Gran Sala del TEDH, que un símbolo religioso en las aulas educativas tiene un papel pasivo, es distanciarse de una idea integral basada en que la presencia de cualquier material curricular afecta la construcción del currículo escolar.

Bajo esta línea se discuten ahora dos opiniones discrepantes de la decisión final de la Gran Sala, así como la posición del Comité de Derechos del niño de la ONU respecto al papel que juega el entorno escolar en la formación integral de las niñas y los niños. Los magistrados Malinverni y Kalaydjieva sostienen que en la escuela pública, el Estado en materia educativa debe actuar con cautela en el sentido en que el conocimiento se transmita en una manera objetiva, crítica y pluralista (TEDH, 2011; Sentencia caso Lautsi, Opiniones discrepantes). Acerca del papel del entorno escolar, los magistrados consideran, de la misma forma en que se argumenta en este trabajo, que dichos principios (la afectación del currículo escolar) previamente señalados no solo son válidos en la elaboración y planificación del currículo escolar, sino también respecto al entorno escolar. Como los muros de las aulas de educación infantil son parte del entorno escolar y por tanto del currículo que allí se construye, aplica y reproduce, se considera que la exposición de símbolos religiosos, como ha quedado demostrado en este trabajo, es una manifestación del distanciamiento de la neutralidad del Estado en materia religiosa que debe ser seriamente revisada. En palabras de los magistrados, el principio de neutralidad estatal en materia religiosa no solo aplica al contenido, sino a todo el sistema educativo. De la misma forma, el 
comentariol del Comité de Derechos del Niño de la ONU (ONU 2001), destaca respecto al ejercicio del derecho a la educación que en el entorno «se incluyen no sólo los elementos integrantes del plan de estudios, sino también los procesos de enseñanza, los métodos pedagógicos y el marco en el que se imparte la educación, ya sea en el hogar, en la escuela u otros ámbitos» (parágrafo 8). A su vez el Comité señala respecto a lo anterior que «el propio entorno escolar debe reflejar la libertad y el espíritu de entendimiento, paz, tolerancia, igualdad entre los sexos y amistad entre todos los pueblos, grupos étnicos, nacionales y religiosos y personas de origen indígena».

Teniendo en cuenta que las niñas y niños en educación inicial son sujetos de derechos, el argumento de la pasividad de los símbolos religiosos vulnera y distorsiona este nuevo concepto, porque supone que las niñas y los niños son meros receptores de unos significados (llámense culturales, históricos, etc.) que son reproducidos en las aulas sin la más mínima crítica. Sin embargo, este argumento y la falta de evidencia sobre la afectación a los menores fueron criterios para mantener los símbolos religiosos en las escuelas públicas italianas. Quitarle valor al carácter fuerte y activo de los mensajes vertidos en los muros de las aulas, es una manifestación de la concepción pasiva del estudiantado, que como sostiene desde hace décadas la investigación social y crítica, el currículo es a todas luces una construcción social y cultural, para nada ajena a la transmisión de significados, entre los participantes y el entorno escolar.

De acuerdo a los resultados del presente estudio, en algunas aulas no solamente hay una presencia única de imágenes religiosas, sino que todas se articulan para transmitir un mismo mensaje. Posiblemente estas representaciones se articulan con otras prácticas. Consideramos que el profesorado puede estar aplicando también la transmisión de estos valores a través de otros materiales didácticos, pero no se cuenta con la evidencia para asegurarlo. Futuros estudios son necesarios que profundicen sobre estas prácticas.

Finalmente como sostiene Tarr, la comunidad educativa en general, y el profesorado en educación infantil en particular, debe analizar críticamente la calidad y la cantidad de los materiales curriculares (comerciales o no comerciales) presentes y expuestos en el entorno escolar y principalmente en los muros de las aulas (92). Las escuelas son un reflejo de las sociedades, fenómeno que reporta un alto grado de diversidad que debe ser respetada. No obstante, en el sistema educativo iberoamericano de la primera infancia y en particular en el colombiano, no existe evidencia, al menos para quienes escriben este documento, de cuáles deben ser las directrices para trabajar la dimensión espiritual y la educación religiosa en el aula de educación infantil. Si esto existiese, los vacíos que existen entre unos y otros, como ha quedado manifiesto en este 
trabajo, permitirían clarificar donde empieza uno y donde termina el otro. En otras palabras, permitiría identificar hasta cierto punto el papel de los mensajes vertidos en los muros de las aulas de educación infantil, si se debaten estos en la crítica ideológica de llevar una religión a una aula de educación pública, o como una manifestación de la participación activa de las familias y de los menores hacia el fenómeno de la diversidad religiosa.

\subsection{Limitaciones}

Dado el carácter exploratorio de esta investigación, este estudio tiene diferentes limitaciones que surgen como oportunidades para trabajos posteriores que quieran continuar con esta línea de investigación. La primera, desconocemos las prácticas curriculares del profesorado de cada aula, razón que evita generalizar sobre la transmisión de otros contenidos con base en las representaciones de las figuras humanas en los muros. En segundo lugar, no tenemos evidencia del efecto que genera en las niñas y los niños en la producción de dichas imágenes, elemento que nos puede dar más información sobre la percepción de estos en su formación. Además, no conocemos si la presencia de esas representaciones es por imposición de la dirección de los centros, de la administración pública o de los participantes, esto es el profesorado y el estudiantado. No obstante estas limitaciones, comunes a cualquier estudio de tipo descriptivo, nuestros resultados, los primeros en el ámbito iberoamericano sobre la presencia de símbolos religiosos en las escuelas públicas, son robustos en señalar que los colegios analizados, en el 50\% de ellos se representan figuras humanas con contenido religioso.

\section{CONCLUSIONES}

Como señala Sanabria, la laicidad no es hostilidad a la religión sino la incompatibilidad con todo privilegio dado a una opción espiritual, sea ésta religiosa o atea (55). En otras palabras como señala Blancarte, «La laicidad no es entonces intrínsecamente anticlerical ni mucho menos antirreligiosa. De hecho, se puede argumentar que ésta surge precisamente como un marco institucional necesario para el desarrollo de las libertades religiosas, particularmente la libertad de creencias y la de culto» (187). Un resultado fundamental de nuestro estudio se vincula con la presencia en los colegios públicos de imágenes vinculadas con la religión católica. Llama la atención la transformación del discurso de presencia religiosa en escuelas públicas, que sobrepasa la representación del crucifijo, como ha sido debatido por tribunales de otros países. Bajo esta óptica, ninguna de las imágenes encontradas hace ilusión a este símbolo, situación que 
nos lleva a concluir que en las aulas de educación infantil en esta ciudad, la presencia de la religión muta hacia un significado más cotidiano, más vinculado con las creencias familiares, tales como la virgen, los ángeles o el divino niño.

No obstante lo anterior, como se ha señalado previamente, estos resultados no pueden ser extrapolados a todas las aulas, pero sí son una evidencia de un comportamiento en principio neutral y anecdótico, que a todas luces tiene consigo una carga ideológica que podría tener un impacto en la formación de las niñas y los niños y sobre todo en el desarrollo de la dimensión espiritual.

De las imágenes analizadas, los colegios no tienen un patrón uniforme sobre la representación de los símbolos religiosos en sus aulas. Este elemento es importante, en la medida en que las representaciones se manifiestan en un importante porcentaje de colegios, más no en la totalidad. Consideramos que este comportamiento obedece más a razones particulares que a una política institucional sobre la presencia de estos símbolos en las aulas.

Desconocemos los criterios sobre los cuáles en las aulas analizadas se representan estos significados, por ejemplo, si es por el proyecto educativo institucional del centro escolar (que en cualquier caso son públicos) o a decisiones personales dentro del currículo que el personal docente considera relevante llevar a las aulas.

Por tanto, si el entorno escolar participa activamente en la construcción del currículo, ¿qué nos está enseñando? (Tarr 2014, 45). De acuerdo a los resultados del presente estudio, los muros transmiten significados vinculados con la práctica religiosa católica y por tanto, distorsionan el principio de neutralidad del Estado toda vez que muestran preferencia en las escuelas públicas por una religión concreta.

A través de la descripción de la presencia de figuras humanas con contenido religioso en los muros de las aulas de educación infantil analizadas, se ha intentado demostrar que estas aulas transmiten un conjunto de valores y creencias acerca de la forma en que se percibe la religión, la dimensión espiritual y el desarrollo del currículo del profesorado y de los centros escolares. Otras preguntas como, qué efecto tienen esas representaciones en el desarrollo de la formación integral del estudiantado, así como cuál es la participación de las niñas y niños para re-construir esos significados, es algo que necesita ser investigado en futuros estudios. 


\section{REFERENCIAS BIBLIOGRÁFICAS}

Alexander, Hanan y Terence McLaughlin. «Education in Religion and Spirituality». The Blackwell Guide to the Philosophy of Education. Ed. Patrick Brantlinger y William Thesing. Oxford: Blackwell Publishing Ltd, 2003, 356-373.

Alvarado-Bedoya, Omar Alejandro. «Laicidad y secularización: la tarea pendiente en la democracia colombiana». Anuario de Derecho Constitucional Latinoamericano 21 (2015): 583-603.

Amérigo, Fernado y Daniel Pelayo. El uso de símbolos religiosos en el espacio público en el Estado laico español. Madrid: Fundación Alternativas, 2013.

Barrera-Rivera, Paulo. «Tensiones entre Pluralismo Religioso y Derechos Humanos en el Brasil Contemporáneo». Revista Religare 12 (2016): 128-151.

Blancarte, Roberto. «América Latina: entre pluri-confesionalidad y laicidad». Civitas-Revista de Ciências Sociais 11 (2011): 182-206.

Bone, Jane. «Breaking Bread: Spirituality, Food and Early Childhood Education». International Journal of Children's Spirituality 10 (2005): 307-317.

Bone, Jane. «Creating Relational Spaces: Everyday Spirituality in Early Childhood settings». European Early Childhood Education Research Journal 16 (2008): 343-356.

Cobos Campos, Amalia Patricia. «La colisión de la libertad religiosa con otros derechos fundamentales: estudio de casos judiciales en México y España». Anuario de la Facultad de Derecho (Universidad de Alcalá) 8 (2016): 37-66.

Constitución Política de Colombia. Gacetas Constitucionales Nos. 114, 116 y 125 de 1991, 1991.

Corte Constitucional Colombiana. Sentencia C-568 de 1993. Bogotá: Corte Constitucional, 1993.

Corte Constitucional Colombiana. Sentencia C-350 de 1994. Bogotá: Corte Constitucional, 1994.

Corte Constitucional Colombiana. Sentencia C-512 de 2003. Bogotá: Corte Constitucional, 2003.

Corte Constitucional Colombiana. Sentencia C-766/2010. Bogotá: Corte Constitucional, 2010.

Corte Constitucional Colombiana. Sentencia C-817 de 2011. Bogotá: Corte Constitucional, 2011.

Corte Constitucional Colombiana. Sentencia C-512 de 2013. Bogotá: Corte Constitucional, 2013.

Decreto 2247 de 1997. Bogotá: Diario Oficial No. 43.131 de septiembre 18 de 1997, 1997.

Grajczonek, J. «"To Thine Own Self Be True”: Respecting Both Religious Diversity and Religious Integrity in Contemporary Australian Early Childhood Religious Education». Global Perspectives on Catholic Religious Education in Schools. Ed. 
Michael Buchanan y Gellel Adrian-Mario. Switzerland: Springer International Publishing, 2015, 103-113.

Harris, Kathleen. «Let's play at the park! family pathways promoting spiritual resources to inspire nature, pretend play, storytelling, intergenerational play and celebrations». International Journal of Children's Spirituality 21 (2016): 90-103.

Haupt, Claudia. «Active Symbols». Boston College Law Review 55 (2013): 821-877. Hermida-Del Llano, Cristina. «La alianza de laicidades». Revista Persona y Derecho 65 (2015): 119-140.

Herrera, Hernán. Alcances de la libertad religiosa y de cultos en la jurisprudencia de la Corte Constitucional Colombiana en el periodo comprendido entre los años 1992 y 2006. Bucaramanga: Universidad Industrial de Santander, 2007.

Hyde, Brendan. «The identification of four characteristics of children's spirituality in Australian Catholic primary schools». International Journal of Children's Spirituality 13 (2008): 117-127.

Ley 133 de 1994. Bogotá: Diario Oficial No. 41.369, de 26 de mayo de 1994.

Ley 115 de 1994. Bogotá: Diario Oficial No. 41.214 de 8 de febrero de 1994.

Lineamientos curriculares de la educación preescolar. Bogotá: Ministerio de Educación, 1997.

Llamazares-Calzadilla, María. Ritos, signos e invocaciones: estado y simbología religiosa. Madrid: Dykinson, 2015.

McLaughlin, Terence. «Education, Spirituality and the Common School». Spirituality, Philosophy and Education. Ed. David Carr y John Aldane. London: Routledge, 2003, 185-199.

Nye, Rebecca, and David Hay. «Identifying children's spirituality: how do you start without a starting point?.» British Journal of Religious Education 18.3 (1996): 144-154.

Organización de Naciones Unidas. Convención sobre los derechos del niño. Adoptada por la Asamblea General de las Naciones Unidas el 20 de noviembre de 1989.

Organización de Naciones Unidas. Comentario 1 del Comité de Derechos del Niño. Propósitos de la Educación CRC/GC/2001/1, Abril de 2001.

Organización de Naciones Unidas. Comentario número 5 del Comité de los Derechos del Niño. Medidas generales de aplicación de la Convención de los Derechos del Niño CRC/GC/2003/5, Noviembre de 2003.

Organización de Naciones Unidas. Comentario general número 7 del Comité de Derechos del Niño. Realización de los derechos del niño en la primera infancia CRC/C/GC/7, Noviembre de 2005.

Pardo-López, María. «Símbolos religiosos y deber de neutralidad estatal: el supuesto de los crucifijos en las aulas como excusa para aproximarse a la relación entre religión y estado». Anales de derecho 26 (2008): 183-225. 
Polo-Sabau, José. «Símbolos religiosos, escuela pública y neutralidad ideológica estatal: el caso del crucifijo». Revista de Derecho Político 85 (2012): 271-292.

Prieto, Vicente. «La laicidad positiva del Estado colombiano». Pensamiento y Cultura 12 (2009): 39-65.

Ranquetat-Junior, Cesar Alberto. «A presença do crucifixo nos tribunais brasileiros: laicidade e símbolos religiosos em discussão». Debates do NER 2 (201120): 97-120.

Sanabria, Fabian. «La laicidad: un requisito para la educación pluralista». Revista Educación y pedagogía 18 (2009): 51-60.

Souto-Galvan, Beatríz. «La interculturalidad en el ámbito educativo español: una perspectiva de género». Revista Latinoamericana de Derecho y Religión 2 (2016): $1-18$.

Strong-Wilson, Teresa y Julia Ellis. «Children and place: Reggio Emilia's environment as third teacher». Theory into practice 46 (2007): 40-47.

Tarr, Patricia. «Consider the walls». Young Children 59 (2004): 88-92.

Tarr, Patricia. «If the Environment Is the Third Teacher, What Is It Teaching Us?». Thinking Critically about Environments for Young Children: Bridging Theory and Practice. Ed. Lisa Kuh. New York: Teacher College Press, 2014, 33-47.

TEDH. Lautsi v. Italy (Lautsi I), App. No. 30814/06, (Eur. Ct. H.R. Nov. 3, 2009), http://www.echr.coe.int/echr/en/hudoc, consultado el 01/07/2016.

TEDH. Lautsi \& Others v. Italy [GC] (Lautsi II), App. No. 30814/06, 10 (Eur. Ct. H.R.Mar. 18, 2011), http://www.echr.coe.intlechr/en/hudoc, consultado el 01/07/2016.

Zoethout, Carla. «Religious Symbols in the Public School Classroom: A New Way to Tackle a Knotty Problem» Religion and Human Rights 6 (2011): 285-290. 